\title{
Hvorfor Fotografistudier? - Fem bud på et svar
}

afprofessor, institutleder, ph.d. Mette Sandbye,

Institut for Kunst- og Kulturvidenskab, Københavns Universitet

Forfatteren er Danmarks forste professor i Fotografistudier. Artiklen er en let bearbejdet udgave afforfatterens tiltradelsesforelasning som professor ved Institut for Kunst- og Kulturvidenskab, Det Humanistiske Fakultet, Kobenhavns Universitet, den 9. juni 2015. ${ }^{1}$ Det Kongelige Bibliotek har som Statens Billedsamling indsamlet fotografier siden det 19. arrhundrede og rummer i dag med omkring 20 mio. fotos den storste samling af fotografier inden for alle typer og genrer i offentlig besiddelse i Danmark. Det Kongelige Bibliotek finder det derfor overordentligt betydningsfuldt, at Københavns Universitet nu har oprettet et professorat på dette felt. (Erland Kolding Nielsen)

\section{Prolog}

Jeg vil indlede denne tiltrædelsesforelæsning med en prolog, og derefter følger fem svar - blandt mange mulige - på dagens overskrift, der jo slutter med et spørgsmålstegn: "Hvorfor Fotografistudier?"

Hvorfor denne overskrift? Fordi jeg i det følgende vil forklare, hvorfor og hvordan en sådan titel giver mening, hvorfor det er et fagfelt, og jeg derfor skriver det med stort $\mathrm{F}$ i titlen på forelæsningen. Og jeg vil gerne forklare, hvorfor jeg har fundet det interessant at beskæftige mig med emnet i de sidste ca. 30 år.

Jeg forestiller mig, at hvis man havde spurgt en arkæologiprofessor om, hvordan hendes interesse startede, så var det måske noget med den flintesten, hun fandt på en mark som barn. For mig går interessen også helt tilbage til sådan noget som at bladre i gamle familiealbum, når jeg som barn var på besøg hos et ældre familiemedlem, eller hjemme fra mine forældres bogreol, hvor der stod et meget slidt eksemplar af kataloget til Family of Man-udstillingen, som min far havde købt, da den blev vist på Charlottenborg i 1957. Da jeg kom på universitetet, søgte jeg viden om og undervisning om fotografi og var noget forundret over, hvor lidt der fandtes. Men jeg skrev en af mine første opgaver på kandidatuddannelsen i Moderne Kultur og Kulturformidling om netop Family of Man-udstillingen, og selvom der ikke fandtes og stadig ikke findes en specifik uddannelse i "Fotografistudier," så lykkedes det mig alligevel at specialisere mig $i$ feltet allerede i min studietid. I anledningen af dagens forelæsning har jeg tilladt mig at skue lidt tilbage. For jeg vil også sige det her til studerende og til yngre forskere end mig: Hvis I finder et emne, som på én gang interesserer jer, og som skriger på at blive taget alvorligt, blive undersøgt, forsket i - så klø på og gør det, gør det selv. For det første kan I gøre en forskel, for det andet er det personligt berigende at finde frem til et forskningsfelt, der kan holde hele livet. Sådan har jeg det med fotografiet.

Da jeg i 1989 skulle skrive speciale, fandtes der skam også specialeworkshops som i dag. Her blev jeg sat sammen med den eneste anden, der også ville skrive om fotografi, Helle Damsgård. Sammen dannede vi det år "Dansk Tværfagligt

1 En stærkt forkortet version har været bragt i Weekendavisen d. 31. juli 2015. 
Fotoforum." Mere end en egentlig stor organisation med et væld af aktiviteter, var det en - med nutidens akademiske lingo - "performativ talehandling:" fordi vi sagde det, så fandtes det. Vi arrangerede 2. maj 1990 et heldagssymposium om fotografi på Det Humanistiske Fakultet med overskrifterne: Hvor på universitetet kan man beskæftige sig med fotografi? Hvordan kan man forske i fotografi? Hvad kan vi sige om fotografi? Er der overhovedet plads til fotografi på humaniora? Det er så det, jeg har brugt de efterfølgende 25 år på at finde svar på.

Vi sørgede selvfølgelig for, at Universitetsavisen reklamerede for feltet med artiklen "Fotografi - et akademisk hittebarn," som indledtes med beskrivelsen: "Bør fotografi ikke være et overbygnings- eller tillægsfag, spørger to studerende fra litteraturvidenskab efter et velbesøgt symposium om det 150 år gamle medium." Her understregede vi den store fagbredde blandt de mange fremmødte, og at fotografi på en gang hører til på antropologi, historie, kunsthistorie og mange andre steder, og at denne allestedsnærværelse muligvis har medført, at ingen rigtig har fundet det værdigt som forskningsobjekt. Dengang for 25 år siden gik jeg med andre ord kraftigt ind for at studere og forske under den meget brede, tværdisciplinært inviterende overskrift "Fotografistudier." Og kan man det? Giver det mening? har jeg funderet over mange gange siden og sat som overskrift for denne tiltrædelsesforelæsning. Netop de år, hvor jeg begyndte at opsøge mere teoretisk viden om og forståelse af det fotografiske medium, kan man tale om en hel eksplosion af akademisk litteratur i feltet, især fra den angelsaksiske tradition. Et pionerværk var John Taggs The
Burden of Representation fra 1988, hvor han gør op med ideen om, at fotografi er noget særligt og med forestillingen om fotografiets privilegerede relation til virkeligheden. Ifølge Tagg kan man ikke tale om en ontologisk enhed, der hedder Fotografi - der findes kun Fotografier, i flertal. Fotografi har ikke en identitet i sig selv, det er et tomt tegn, og fotografier eksisterer ikke udenfor diskursen. Det er altså den sproglige forankring, der bestemmer et fotografis betydning. Mange taler om fotografi som et urent medium, Richard Bolton (Bolton 1989, xi) kalder det føjeligt, "adaptable," fordi et givent fotografi kan betyde hvad som helst alt efter konteksten. Fotografi er ontologisk ustabilt.

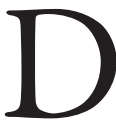
et findes der masser af eksempler på op gennem historien, ikke mindst på fotografier der er skabt ind i en meget specifik, ofte instrumentel kontekst, men som siden er gledet ind $\mathrm{i}$ kunstfeltet med helt andre betydninger: JH Lartigues familiefotos taget af et barn i Frankrig omkring forrige århundredskifte, Arnold Odermatts politifotos fra 1950-60'erne, der sælges til skyhøje priser på kunstmarkedet, Mary Willumsens erotiske postkort fra omkring 1920, der blev solgt ulovligt under bordet i de runde kiosker på Rådhuspladsen, og som der også er gjort senere forsøg på at få indlemmet $i$ en mere formorienteret modernistisk kunsthistorie. Eksemplerne er legio. Da jeg kørte et introducerende metodisk og teoretisk kursus på kandidatuddannelsen i Moderne Kultur og Kulturformidling for nogle år siden, hvor målet var at indkredse uddannelsens kerne, kunne jeg ikke lade være med give fotografiet en helt central placering, fordi det 
netop på én gang er lav- eller folkekultur $o g$ finkultur. Fotografi er et massemedium omspundet af stærke diskursive magtrelationer - og for at gennemskue dem må man vide noget om mediets historie og virkemåde. Endvidere er fotografi enormt udbredt som folkeligt medium, ligesom det har stået helt i front i billedkunsten de sidste mange tiår. Hvis man arbejder kunstnerisk med et medium, så skal man kende dets historie, dets materialitet, dets virkemåde, også selvom man på avantgardevis bryder med det hele.

I grunden er det min overbevisning, at det netop er uafgørligheden, den ontologiske ustabilitet, som på én gang er fotografiets største styrke og dets største akademiske udfordring. Her vil jeg nøjes med at forsøge at give fem svar på spørgsmålet om, hvorfor man skal have en professor i Fotografistudier - eller bare 'hvorfor Fotografistudier?' Det er svar, der spænder fra det konkrete institutionelle niveau til det mere eksistentieltfilosofiske:

1. Et institutionelt svar.

2. Et erkendelsesfilosofisk, fænomenologisk svar, der især knytter sig til nyere tids kunstneriske brug af fotografi.

3. Et svar relateret til en af de allermest udbredte former for fotografi, nemlig familiefotografi.

4. Et svar foranlediget af den digitale eksplosion og behovet for en ny medieøkologi: Hvad betyder det for vores liv, at det er så gennemfotograferet, og at vi deler fotografierne med andre. Hvilke erkendelser rummer sådanne billeder, både for det enkelte individ og for den bredere offentlighed? Det er spørgsmål, jeg blot vil antyde, og som råber på forskning bedrevet af folk med en baggrund i de kulturvidenskabelige fag.

5. Og endelig det korte afsluttende svar, som jeg allerede nu vil foregribe: fordi vi slet ikke er færdige med at diskutere fotografiet som sprog.

\section{Institutionernes rolle}

"Den bedste fotograf, De aldrig har hørt om." Sådan lød overskriften i det engelske tidsskrift Creative Review til en stort opsat og meget begejstret artikel om den danske fotograf Keld Helmer-Petersen, der blev født i 1920. Artiklen udkom blot nogle år, før han døde i 2013. Bladet er ved at boble over af begejstring. Tidsskriftets leder handler om Helmer-Petersen, og her fortæller redaktøren, hvordan et tidsskrift altid drømmer om at opdage et gemt eller glemt geni, og hvordan denne drøm blev til virkelighed, da de så bogen Keld Helmer-Petersen. Photographs $1941-$ 1995 (2007). "Petersen er den pludseligt ankomne inkarnation af denne fantasi," skriver redaktøren, og de fortsætter med at rose hans værker for at fremstå så friske og moderne som dengang, de blev taget. Han kom "i stald" hos Londongalleriet Rocket Gallery, da han var tæt på de 90. Hans legendariske fotobog 122 Farvefotografier fra 1948 blev genudgivet på et amerikansk forlag kort før hans død.

Det er i den grad USA, der har domineret den internationale historieskrivning om fotografi - de har haft museer og uddannelser, og de skabte tidligt en kanon og satte amerikansk fotografi ind som det centrale i hele verdens fotografihistorie. Alt det har understøttet udviklingen af amerikansk fotografi. Havde HelmerPetersen været amerikaner, var han for længst - og ikke i en alder af 90 - blevet 


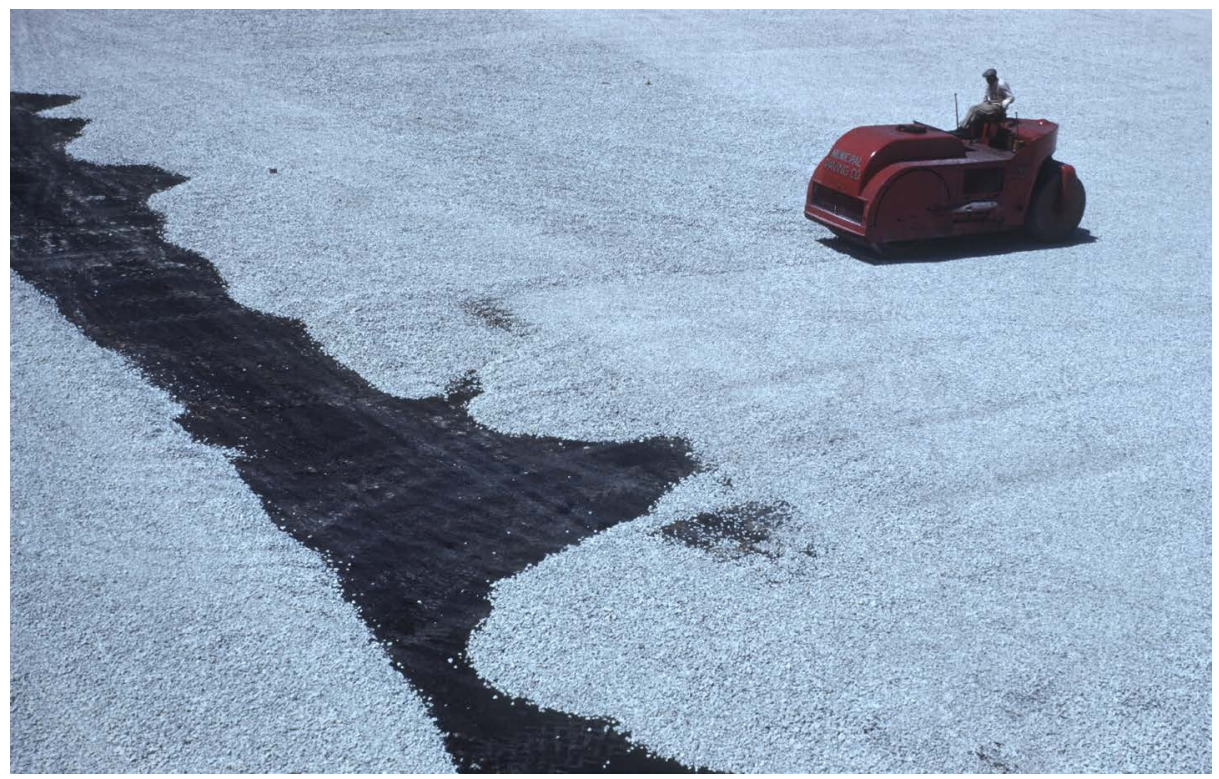

Keld Helmer-Petersen: Motiv fra rejse til USA (Chicago, San Francisco, Arizona), 1950'erne. Det Kongelige Bibliotek, Billedsamlingen.

verdensberømt, og hans værker kunne ikke længere erhverves for et par tusind, som de stadig kan i dag. Forskningen skal ikke arbejde for kunstmarkedet og for at presse priserne i vejret for danske fotografer, men jeg bruger eksemplet for at pege på, at fotografiet altid, men dog i mindre grad i dag end da Helmer-Petersen var ung, har været uhyre svagt forankret institutionelt i Danmark. Allerede før lanceringen af den nye teknik i 1839, havde den danske arkæolog Christian Tuxen Falbe besøgt fotografiets opfinder Daguerres atelier, han sendte straks et brev om den nye teknik til den danske kronprins Christian Frederik, og i det hele taget spredte fotografiet sig til Danmark med lynets hast. Men hvad var fotografi, og kunne man anerkende det som kunst, spurgte man sig selv? I januar 1843 bad man om Kunstakademiets syn på sagen, og herfra udtalte man officielt at nej, det kunne det ikke, det hørte under naturvidenskaben. I 1846 kom der dog en ny erklæring fra den kant om, at det var ok at betragte fotografi som håndværk (se Dansk Fotografihistorie).

Det var det så i mange, mange år herhjemme. Blandt andet viste Kunstindustrimuseet, i dag Designmuseum Danmark, fotografiske udstillinger fra 1960'erne og frem, men klassificeret som "anvendt kunst." Vi skal faktisk helt frem til 1974, hvor Viggo Rivad som den første fotograf tildeles Statens Kunstfonds 3-årige legat, og samme år ændres fondens fundats, så netop fotografi kan støttes som kunst. Året efter, i 1975, åbner Charlottenborgs legendariske censurerede forårsudstilling for fotografi, og $\mathrm{i}$ 1980 bliver den første ansøger optaget på Kunstakademiet i København udelukkende på indsendt fotografi, nemlig Per Bak 
Jensen. I 1987 åbnede Museet for Fotokunst i Odense. Før det havde vi kun haft Galleri Image i Århus, åbnet i 1977, som ti år efter fik en københavnsk pendant, Fotografisk Galleri (lukket 1997). Fotografisk Center, som stadig eksisterer, blev åbnet, da København i 1996 var europæisk kulturby. Det Nationale Fotomuseum på Det Kongelige Bibliotek blev oprettet 1996, men fik først egne udstillingssale i 1999. Museets og bibliotekets samling er en af Nordeuropas fineste, og her ligger et enormt righoldigt materiale til mange studerendes og forskeres beskæftigelse fremover. Udviklingen af dansk fotografi og dets institutionelle forankring blev for første gang beskrevet samlet i Dansk Fotografihistorie, som udkom i 2004.

Men fotografiet gisper stadig efter vejret i Danmark: I 2014 blev Museet for Fotokunst i Odense indlemmet i den nye institution Brandts, Museum for Kunst og Visuel Kultur. Museumstidsskriftet Kata$\log$ blev nedlagt af museet og fortsætter nu som privatdrevet, Det Nationale Fotomuseum har kun råd til to årlige udstillinger, og hvis der for alvor skulle forskes i husets fornemme samling, ville det kræve en kraftig tilførsel af ressourcer. Fotomuseet i Herning er lukningstruet, fordi kommunen vil spare det årlige tilskud på 600.000 kr. Museet er især kendt for at have en meget fin teknisk samling.

I efteråret 2011 blev den tyske fotograf Andreas Gurskys fotografi "Rhein II" fra 1999 solgt på auktion for 4,3 millioner dollars. Det var på det tidspunkt verdens dyreste fotografi. Fotografiet indledte Louisianas store Gurskyudstilling, der åbnede et halv års tid efter og betimeligt viste sådan en kunstner i den helt øverste verdensklasse. I udstillingsformidlingen så Louisiana sig imidlertid nødsaget til gang på gang at understrege, at han er kunstner mere end bare fotograf "på den gammeldags måde," som direktørens skrev, og "at arbejde med Andreas Gursky og hans fotografi er at arbejde med sand visuel kunst - kun ved eftertanken går det op for én, at mediet er fotografi," som der også stod på den indledende vægtekst. Efterfølgende betones ganske vist vigtigheden af, at det er fotografi, men igen forklares det så undskyldende, at "det er denne fordybelse i billedets næsten ubegribelige detaljerigdom, der berettiger hans tilstedeværelse på et museum for moderne kunst." Der burde ikke i 2012 være grund til at skulle forklare, at fotografen skam er kunstner "inden han er fotograf," og at "Gurskys fotografier er billedkunst," som det hed i pressemeddelelsen. Ville man nogensinde skrive det samme om malere som Kirkeby eller Kiefer?

Hvis vi ser udover Norden, er det især lykkedes for finsk fotografi at markere sig i den store verden. Især i 1990'erne og nullerne formåede hele miljøet - fra kulturministerielle programmer som Frame og skoler som University of Art and Design i Helsinki, fotocentre rundt i landet, brandet "The Helsinki School" og til de enkelte fotografer - at synliggøre finske fotobøger, finsk landskabsfotografi, kvindelige finske videokunstnere som Eija-Liisa Ahtila og Salla Tykkä og den - på det tidspunkt nye - form for rå socialdokumentarisme, som f.eks. Pekka Turunen og Esko Männikkö står for. Det er også det finske institutionelle miljø og ikke det danske, der har understøttet en dansk fotograf som Joakim Eskildsen, der lige nu viser en fornem udstilling på Det Nationale Fotomuseum i København. På både institutions- og uddannelsesniveauet ligger ligeledes både Norge og Sverige 


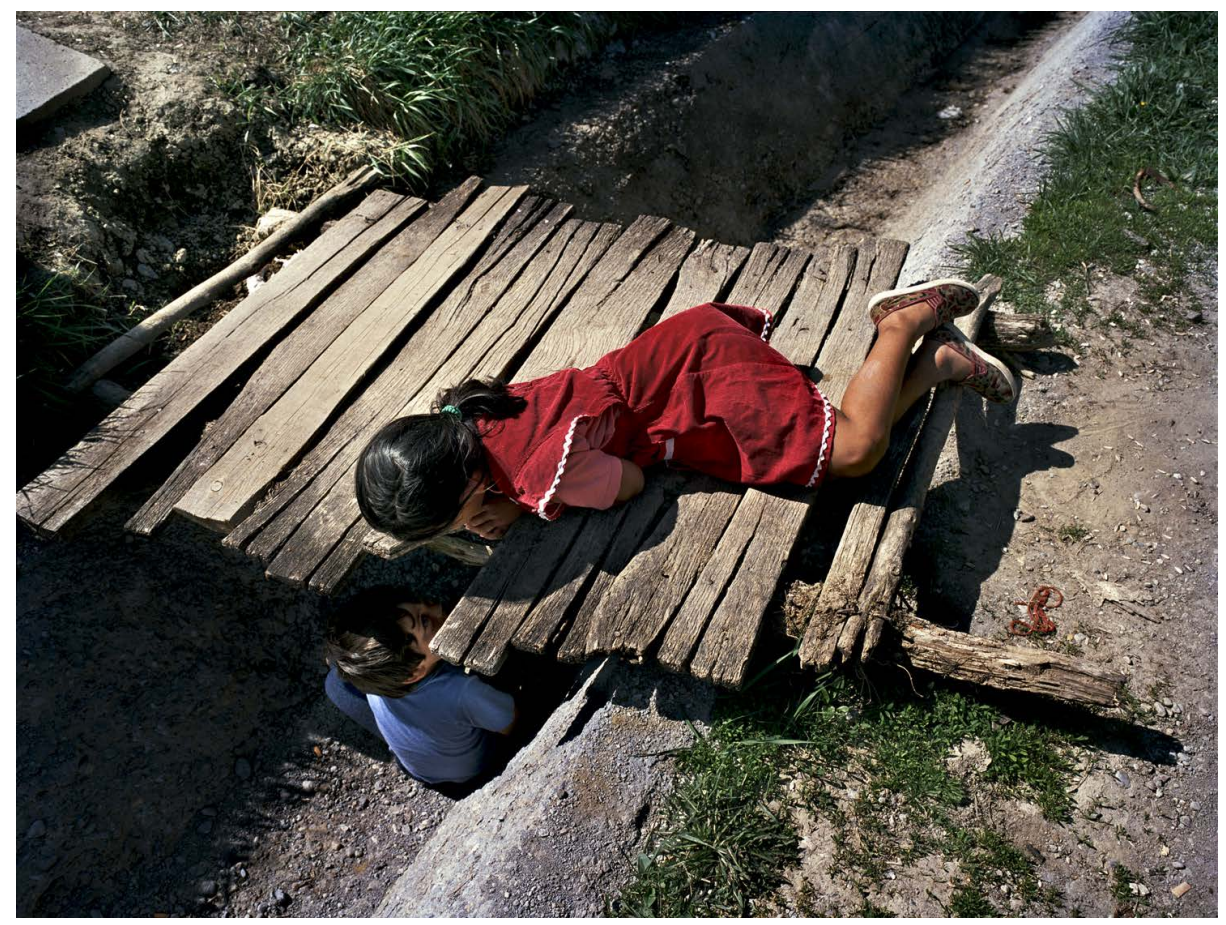

Joakim Eskildsen: Fra The Roma Journeys. Serien er en del af udstillingen "Joakim Eskildsen: En verden jeg kan tro på," som vises på Det Kongelige Bibliotek frem til 30. januar 2015.

foran Danmark. I Danmark har den institutionelle indramning om fotografiet (universiteter, skoler, museer) som nævnt altid været svag, hvorfor dansk fotografi $i$ langt mindre grad har markeret sig med synlige, identificerbare skoler og strømninger. Jeg vil forlade dette argument nu, men jeg mener, at det også er akademias rolle at kvalificere en sådan diskussion, der rækker ud i en bredere offentlighed.

\section{Fotografi som filosofisk erkendelse}

Mit erkendelsesfilosofiske svar på spørgsmålet "Hvorfor Fotografistudier?" har at gøre med fotografiets udbredelse i billedkunsten i den tid, jeg har arbejdet med det. For mig har arbejdet med billederne, værkerne, altid kommet før teorien, men det er så netop billederne, der har fungeret som en indgang til at tænke teorien. Den vestlige tænkning og fænomenologien i særdeleshed har i århundreder kæmpet med at forstå menneskets forhold til tiden og opsplitningen mellem den rationelle, kosmologiske, målbare tid og den sansede, psykologiske, personligt erfarede tid. Allerede kirkefaderen Augustin taler omkring år 400 e.K. om tiden i værket Bekendelser. Hvis ingen spørger mig om det, ved jeg det. Hvis jeg skal forklare det for en, der spørger, ved jeg det ikke, siger Augustin (Sandbye 2001). Tiden er ikke noget, man objektivt kan måle, men noget, man kan mærke med sjælen som en erindring om fortiden eller en forventning til fremtiden, som imidlertid begge rela- 


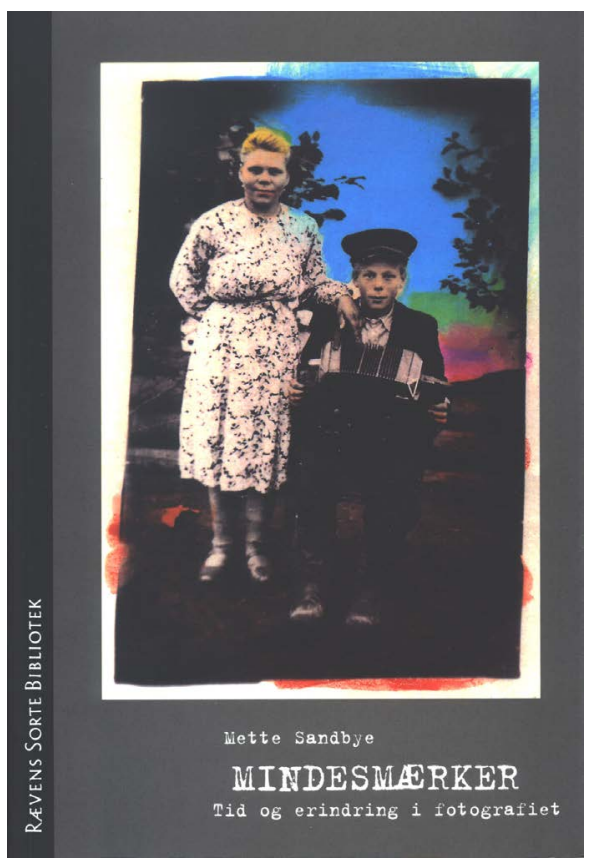

"Fotografiets mentale realisme." Mette Sandbye: Mindesmærker. Tid og erindring i fotografiet, 2001. Forsidefotografi: Boris Mikhailov, Luriki 1975-85.

terer til det nu, man lever i. Tid er noget, som især fænomenologerne fra omkring forrige århundredskifte har beskæftiget sig med, og f.eks. Heidegger taler om, at det er en vigtig erkendelse for mennesket, at vi lever over tid, fra fødsel til død. Så man kan konstatere mindst to erkendelsesfilosofiske eller psykologiske spørgsmål, som mennesket bakser med, og som fotografiet - der fastfryser tiden for evigheden - er eminent til at hjælpe os med. Det ene er altså, hvad tid er, og hvad det vil sige at leve over tid, på vej mod døden. Det andet, som Geoffrey Batchen skriver om i sit pionerværk Burning with Desire (1997), er den subjekt-objektrelation, der opstår en vis usikkerhed om i mennesket omkring Oplysningstiden i 1700-tallet og Romantikken i begyndelsen af 1800-tallet. På det tidspunkt var hverken natur/ omverden og på den anden side mennesket så stabile entiteter, som man før havde tænkt dem, og relationen mellem dem blev i stigende grad opfattet som ustabil. Hvordan gengiver man indsigten $i$ at være et aktivt, selvrefleksivt, skabende jeg i en foranderlig, levende verden? Det var disse filosofiske grundlagsproblemer, som fik videnskabsmænd, kunstnere og opfindere til at "tænke fotografiet," som Batchen kalder det. Fotografiet billedgør en ny, moderne erfaring af tidens mangfoldighed og af en ustabil, bevægelig relation mellem mig og omverden, hvilket også var en grund til dets enorme popularitet allerede fra samme dag, som Louis Daguerre overdrog sin opfindelse til den franske stat i august 1839.

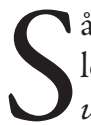
å mere end det, at fotografi handler om at gengive verden, som den virkelig var, som er en egenskab, der har klæbet til mediet siden dets fødsel og besværliggjort en mere nuanceret forståelse af det, har det for mig handlet om at analysere, diskutere og teoretisere over disse mere erkendelsesfilosofiske aspekter af mediet. "Fotografiets mentale realisme," som jeg kalder det i bogen Mindesmarker. Her har samtidskunstens brug af fotografiet været et vigtigt og interessant sted at hente en sådan nuanceret forstålse for fotografiets komplekse virkemåde i forhold til tid og erindring. Kunstnere som Christian Boltanski, Art Spiegelman og Shimon Attie har approprieret private billeder og historiske arkivfotografier for at forstå og bearbejde traumatiske aspekter af den nære kollektive historie, her Holocaust, på en ny, åbnende, dynamisk fortællende måde. 


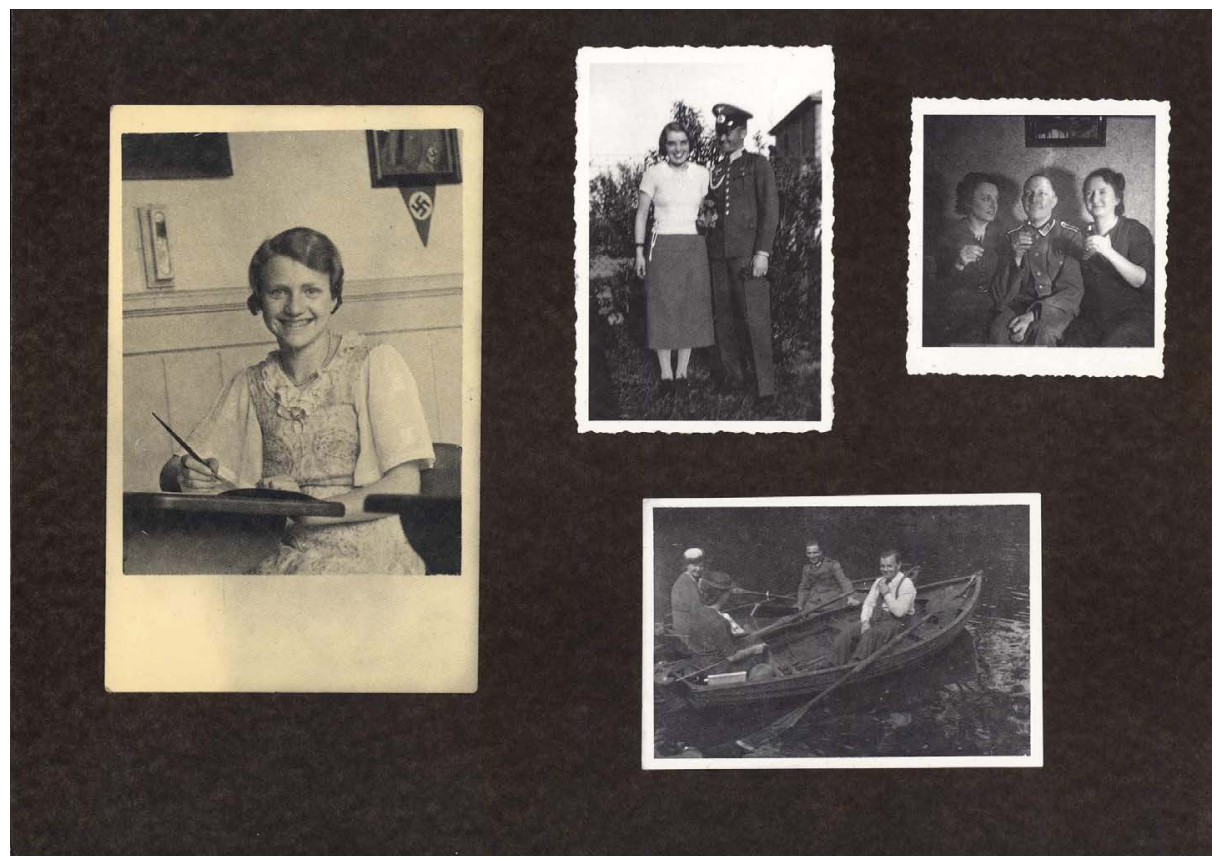

Fra Christian Boltanskis bog Sans-Souci, 1991. Bogen er en gengivelse af et tysk familiefotoalbum fra 1930-40'rne med naziflag og uniformer som en del af hverdagslivet.

Kunstnere som Pia Arke og Igor Savchenko har brugt fotografiet til at åbne op for en personlig fortolkning af andre voldsomme historiske konflikter og traumer såsom koloniseringen af Grønland og konstruktionen af og opløsningen af Sovjetunionen. Det Nationale Fotomuseum huser i øvrigt Pia Arkes efterladte værk.

\section{Familiefotografiets enorme udbredelse} Arbejdet med kunstnernes anvendelse og bearbejdning af familiefotografi fik mig til at gå på jagt efter litteratur om "rigtigt" familiefotografi, som i virkeligheden er den mest udbredte form for fotografi overhovedet siden 1880 'erne, hvor det amerikanske firma Kodak lancerede det lille bokskamera Box Brownie med rullefilm under sloganet "You press the button, we do the rest." Men der fandtes overraskende lidt litteratur om familiefotografi. Familiealbumkulturen er næsten lige så gammel som fotografiets historie. Familiefotografiets udbredelse som genre hænger tæt sammen med den borgerlige kernefamilies opståen og cementering som selve individets base i kølvandet på industrialisering, modernisering og urbanisering op gennem 1800-tallet.

I begyndelsen, altså omkring 1860, bestod albummet som regel af portrætter taget af en professionel fotograf, ikke mindst efter det relativt billige visitkortfotografis opfindelse og udbredelse op gennem 1860'erne. Men det var relativt dyrt at fotografere og erhverve et kamera, så vi skal faktisk helt frem til 1950-60'erne, før det for alvor blev almindeligt at eje et kamera 


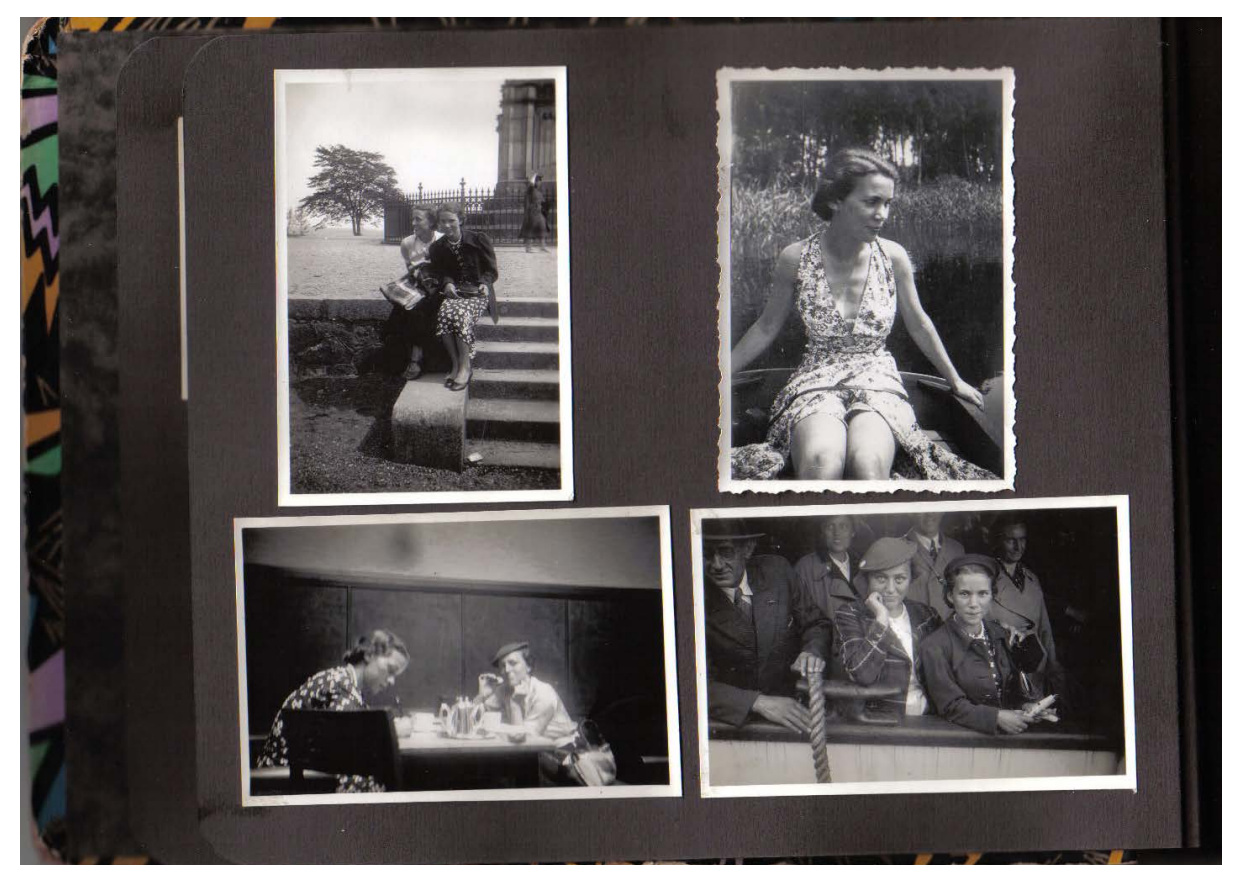

Anonymt dansk familiealbum fra 1940'rne.

og fotografere ofte, selv blandt kvinder og børn. I 1945, da krigen sluttede, importeredes færre end 200 kameraer til Danmark, i 1960 var tallet steget til 130.000, og siden gik det fremad med lynets hast (se Dansk Fotografihistorie). Mediet var nu ikke længere forbeholdt de rige og de professionelle, det var blevet en del af dagligdagen og fritidskulturen. I 1960'erne kom farvefilmen og de billige "Instamatickameraer" med film leveret i en kassette, der kunne sættes direkte i apparatet og forholdsvist hurtigt kunne fremkaldes hos den lokale fotohandler. Og ligesom man med udviklingen af velfærdssamfundet i den periode afsatte penge til fritidskultur, valgte et bredt udsnit af befolkningen at bruge penge på selv at dokumentere hverdagen og familien. Det var i den periode, at det at fotografere for alvor blev en del af også børns og unges hverdag, og datidens mest udbredte konfirmationsgave var et fotoapparat.

I de sidste par tiår har man kunnet opleve en masse udstillinger af historisk familie- og amatørfotografi på kunst- og fotografimuseer verden over, ligesom museer overalt i deres bestræbelser på inklusion inddrager folks private familiefotos, selfies osv. Fælles for de fleste af disse udstillinger - og de tilhørende kataloger og bøger - er, at familiefotografierne og de mange amatørsnapshots præsenteres ukontekstualiseret og isoleret fra hinanden, og hvis der er en tekst, beskrives de i et nostalgisk tonefald som poetiske, charmerende, mystiske, sjove, uskyldige, kulturelt ufordærvede, hverdagslige øjebliksbilleder. Men jeg vil hævde, at det at lave et familiealbum er en måde at forstå 
og erkende tiden og sig selv i og over tid. Det moderne individ skaber orden på sin tilværelse, skaber forbindelser, sætter sig selv ind $i$ en større sammenhæng, fortæller og forhandler sin egen historie - i relation til den store historie.

Problemet med de ovennævnte udstillinger - og megen litteratur om familiefotografi - er, at familiealbummet sjældent studeres i sin helhed, som en samlet, personlig, narrativ praksis, og sjældent analyseres i forhold til brugen af det. Der fokuseres også alt for sjældent på fotoalbummet som et materielt objekt, der er forbundet med meget mere end det enkelte billede. I de senere år er der imidlertid kommet mere fokus på denne side af albumkulturen. Bl.a. den canadiske kunsthistoriker Martha Langford, den engelske antropolog Elizabeth Edwards og den engelske geograf Gillian Rose har i forskellige sammenhænge påpeget vigtigheden af at betragte familiealbummet som et materielt - på én gang dybt emotionelt og banalt - objekt, der forbinder mennesker med hinanden og oftest er knyttet til og afhængig af en mundtlig fortælling. Igen vil jeg fremhæve en institution som Det Kongelige Bibliotek, men også et hav af andre arkiver, museer og lokalhistoriske samlinger, der rummer et enormt - men uudforsket - materiale. Selv har jeg for eksempel studeret turistalbum på Det Kongelige Bibliotek. Den type album er et interessant fænomen, der bla. handler om at tæmme og oversætte det fremmede, men også som historisk fænomen kan bruges til at analysere samtidens værdier og affekter. Et andet interessant spørgsmål, jeg selv har arbejdet med, bl.a. ved at tage på feltarbejde i Japan, er, om man kan tale om en global Kodakkultur, eller hvordan kulturelle og geografiske forskelle udspilles i familiealbummet?

Men hvad sker der så, når det private fotografi ikke længere samles $i$ album i reolen, men spredes ud på diverse websites? Det leder mig over til argument nummer fire.

\section{Den digitale revolution}

Jeg har især beskæftiget mig med familiefotografi i den tidlige velfærdsstat. Det næste store skred i familie- og snapshotfotografiets udvikling sker med de digitale kameraers udbredelse i 1990'erne, hvor man nu pludselig kunne tage et hav af billeder, se dem lige med det samme og straks slette alle dem, man ikke brød sig om. Med de analoge kameraer skulle filmen først fremkaldes, og hvert enkelt billede kostede omkring 5 kroner. Det digitale snapshotfotografi eksploderede for alvor for ti år siden med to nye teknologier: smartphonen og de sociale delingssites på nettet. Ifølge en artikel i det amerikanske magasin Business Insider (18. september 2013) uploades der hver dag 350 millioner fotografier alene på Facebook, et tal der ikke engang inkluderer det Facebook-ejede Instagram (Larsen og Sandbye 2014). Udbredelsen af snapshottet hænger sammen med, hvor nemt det er at dele dem med andre. Stort set alle mennesker, med undtagelse af de allermindst bemidlede, tager digitale snapshots. $\mathrm{Og}$ mange - især de unge - deler dem med andre som det vigtigste formål med dem. På Facebook, Instagram og alle de andre sociale fotodelingssites ser man masser af fotografier af tilsyneladende ubetydeligt hverdagsliv udenfor det særligt rituelle, ophøjede og festlige; fotos af morgenmad, boligindretning, hverdagslivsdetaljer og ikke mindst selvportrætter. Men samti- 


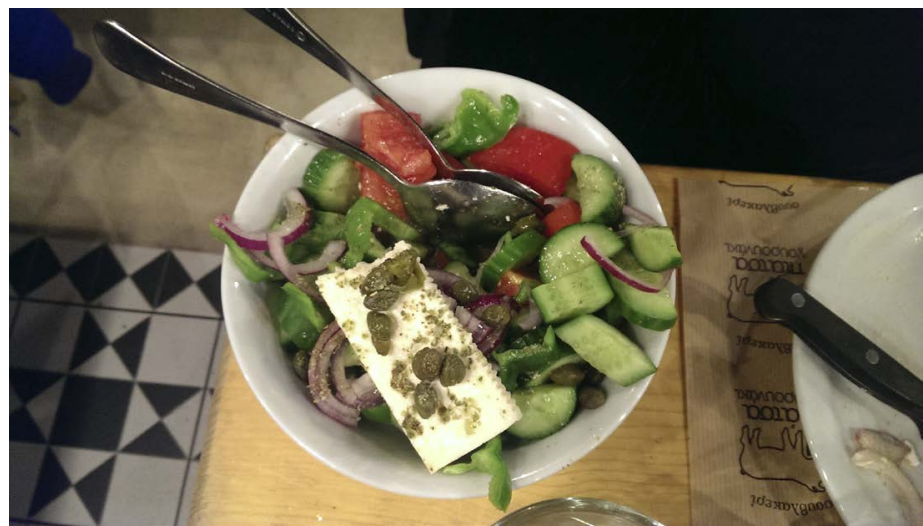

"Se hvad jeg spiser på restaurant $p a ̊$ Cypern lige nu og her." Instagramsnapshot taget med smartphone (ved forfatteren).

dig er der også blevet rum for at fortælle andre historier: Om seksuelle eller etniske minoriteter, teenageliv, hverdagsperspektiv på krig, traumebearbejdning og meget andet.

\section{$\mathrm{E}$}

$\mathrm{t}$ af fototeoriens teoretiske pionerværker er Roland Barthes' bog $\mathrm{La}$ chambre claire fra 1980 eller Det lyse kammer, som den hedder på dansk. Her finder Barthes ind til fotografiets essens, som er dets gengivelse af "det der har været," der som en smertende pil rammer os i hjertet og minder os om, at vi i sidste ende alle skal dø. Fotografi er et memento mori, og det vil altid være forbundet med en følelse af melankolsk tab overfor det tabte, livløst frosne nu. Men igen er det billederne, der kan lære os at formulere og nuancere teorien om fotografiet som medium. Med den på én gang markant øgede og temmelig anderledes brug af fotografi både i kraft af smartphonen, dens allestedsnærværende internetopkobling og de mange sociale delingssites på nettet, skal vi i langt højere grad forstå fotografi som noget andet: Først og fremmest som en social teknologi, der handler om at mødes, udveksle, forme og forhandle identiteter og dele et "nu," lige mens det sker, fremfor noget "der var engang." Snapshottet er for alvor blevet "det hurtige skud," der mere end at tilfredsstille et "mumiebegær," som den franske filmteoretiker André Bazin i 1945 beskrev fotografiets evne til at balsamere tiden, forbinder os - som en del af en social hverdagsaktivitet - i et øjeblik, der leves lige nu og her. Og hvis fotografiet før blev forbundet med sorg og melankoli over det tabte, skal vi snarere forbinde en social og eksalteret følelse af affekt med mediet i de nye, hurtige delingsformer.

Med den analoge teknik forevigede man oftest en situation i et enkelt eller to snapshots, som blev fremkaldt og sat i albummet, næsten lige meget hvor dårligt det var. Herefter blev albummet kun taget frem indimellem og samlede ellers støv på hylden. I dag kan man finde stimer af sådanne private familiealbum direkte tilgængelige for enhver på nettet. Og ikke nok med at de er tilgængelige for alle, man finder ofte en uhyre stor mængde billeder taget af den samme situation. På delingssitet Picasa finder jeg for eksempel den amerikanske kvinde Helens digitale familiealbum. I en "undermappe" betitlet 
"Family cook out and boating trip" har hun lagt 200 fotografier, hvoraf over hundrede er optaget over en times tid i en swimmingpool, hvor Helen, hendes mand og deres to børn leger og bader, og i endnu hundrede snapshots ser man de to drenge med redningsveste på en bådtur. Fotografierne er optaget med ultrakorte tidsintervaller, og den slags snapshotsamlinger er ikke usædvanlige at støde på, hvis man bare sidder og bladrer på nettet i en times tid. Fremfor at fremmane en "barthesk" eller "bazinsk" nostalgisk balsameret fortid sætter disse nærmest filmiske sekvenser sikkert Helens slægtninge, der ikke var med på turen og i swimmingpoolen, i en meget nærværende kontakt med den lille familie, der opleves "som om man var der selv." Fotografiet er gået fra at være en dateknologi til at blive en nu-teknologi.

Noget lignende kan anføres om fænomenet selfies. Lige siden fotografiets opfindelse har der fandtes selvportrætter. Et af fotografihistoriens mest berømte er af den franske fotografipioner Hippolyte Bayard, der i 1840 iscenesatte sig selv som en druknet mand i ærgrelse over, at $\mathrm{Da}$ guerre var kommet først med offentligt at lancere den opfindelse, som Bayard også arbejdede på og faktisk var tidligere ude med end Daguerre. Men det er først for nylig, at denne særlige men århundredgamle afart af det fotografiske selvportræt fik sit nye navn "selfie," og det hænger sammen med den digitale udbredelse og deling på nettet.

I dag er et af de mest udbredte snapshotmotiver, især blandt unge, selvportrættet. Ved udgangen af 2012 udråbte Time Magazine ordet selfie til et af årets "top 10 buzzwords." Næsten et år efter, d. 19. november 2013, udsendte det estimerede Oxford Dictionaries en pressemeddelelse, hvor de meddelte, at ordet selfie var "årets ord," fordi dets anvendelse var steget $17.000 \%$ på blot et år. Siden da har man kunnet læse mange avisartikler, hvor alt fra bekymrede forældre til psykologer har advaret mod, at denne overdrevne selvfotografering er udtryk for en ekstrem narcissisme, hvor unge er fanget i en endeløs (og falsk) selviscenesættelse og spejler sig i tidens forskruede og løgnagtige køns- og kropsidealer. Især unge med lav selvfølelse skaber selfies, advarer psykologer, og fotografierne kan stå $i$ vejen for opbygningen af rigtige sociale relationer i "det virkelige liv."

Naturligvis er mange unge ofre for selvspejlinger i et forskruet kropsbillede gennem medierne, ligesom antallet af unge med anoreksi er stigende. Men fænomenet selfie må være mere kompliceret end som så, siden det og i det hele taget det digitale snapshot er blevet så udbredt. Det handler som regel og langt hen ad vejen om at bruge fotografiet som et spejl, undersøge sig selv, lege med roller - også de grimme og vrængende, finde sig selv $i$ et umådeligt mulighedsfelt af roller og selvfremstillinger og udveksle disse "billedundersøgelser" som en del af det at være et socialt væsen $i$ et netværk af og med andre sociale væsener. Det handler igen om at anvende fotografi som erkendelsesfilosofisk redskab til at lære at være menneske. Så for at kæde argument 3 og 4 sammen: I "gamle dage," dvs. for kun tifemten års tid siden, måtte man lede efter sådanne private snapshots i lokalhistoriske arkiver, på loppemarkeder og i private hjem. I dag ligger der et enormt materiale på nettet fra Danmark og hele verden, frit tilgængeligt for alle og enhver. Det er bare om at dykke ned i denne enorme 
billedkultur og begynde at hive nogle af de indsigter ud, som fortæller os om det levede hverdagsliv i går og i dag.

\section{Konklusion}

Alene Det Kongelige Biblioteks samling rummer knap 20 millioner analoge fotografier (ultimo 2014). Læg dertil fotografiets enorme udbredelse på internettet, $\mathrm{i}$ hverdagskulturen og i samtidskunsten. Der er nok at tage fat på for forskningen. Mit femte svar på spørgsmålet om, hvorfor det er vigtigt, at der bedrives fotografistudier, lyder derfor således: Fordi fotografi stadigvæk er et ungt medium, og vi slet ikke er færdige med at finde ud at, hvad det er, det kan og gør og hele tiden udvikler sig til. Vi lever i en billedkultur, og fotografiet er en af de vigtigste formidlere og fortolkere af verden - fra at vise os konsekvenserne af krig og naturkatastrofer som tsunami og jordskælv, til hvad kæresten spiste til morgenmad, eller hvordan vores endnu ufødte barn ser ud.

Det (heldigvis) ustabile og bestandigt uafklarede forhold mellem kunst og dokumentar eller mellem professionelle billeder og amatør- eller allemandsfoto-

\section{Referencer}

Barthes, R. 1983 [1980]. Det lyse kammer.

Batchen, G. 1997. Burning with Desire. The Conception of Photography. Cambridge, MA.

Bolton, R. 1989. "Introduction." I Bolton (ed.), The Contest of Meaning: Critical Histories of Photography. Cambridge, MA.

Edwards, E. og J. Hart (eds.) 2004. Photographs. Objects. Histories. On the Materiality of Images. London/New York.

Langford, M. 2001. Suspended Conversations: The Afterlife of Memory in Photographic Albums. Montréal.

Larsen, J. \& M. Sandbye (eds.) 2014. Digital grafi - for bare at nævne to af fotografiets mest centrale og væsentlige dialektikker - skaber bestandigt problemer. I forhold til at anerkende fotografi i museums- og kunststøtteverdenen, i forhold til kildekritik på de sociale medier og for så vidt også bredt på internettet og såmænd også i den trykte presse (hvad kan man stole på?), i forhold til at forudsige, hvor den eksploderende fotografikultur bevæger sig hen, og om den er bekymrende og ligefrem farlig, i forhold til hvordan man kan undervise i emnet i folkeskoler og gymnasier (det møder jeg mange, der har svært ved). Så min opsummering af fem svar - blandt mange mulige - på spørgsmålet "Hvorfor Fotografistudier?" lyder: Fordi der er brug for institutionel forankring for dansk fotografis udvikling. Fordi fotografiet hjælper os med at forstå og erkende, hvad det vil sige at være menneske og leve over tid. Fordi familiefotografiet er en af den moderne kulturs mest udbredte billedformer. Fordi fotografiet undergår en enorm forandring i netop disse år. Fordi vi slet ikke er færdige med at diskutere, forstå og nuancere, hvad dette - historisk set stadig nye medium kan og gør.

Snaps. The New Face of Photography. Lond. Rose, G. 2010. Doing Family Photography. Aldershot.

Sandbye, M. 1992. Det iscenesatte fotografi.

Sandbye, M. 2001. Mindesmarker. Tid og erindring i fotografiet.

Sandbye, M. (red.) 2004. Dansk Fotografihistorie.

Sandbye, M. 2007. Kedelige Billeder. Fotografiets snapshotestetik.

Steichen, E. 1955. Family of Man. New York.

Tagg, J. 1988. The Burden of Representation. Minnesota. 